\title{
BMJ Open Mapping precision public health definitions, terminology and applications: a scoping review protocol
}

\author{
Rebecca Bosward (D), Annette Braunack-Mayer (D), Emma Frost (D), \\ Stacy Carter
}

To cite: Bosward R, BraunackMayer $\mathrm{A}$, Frost $\mathrm{E}$, et al. Mapping precision public health definitions, terminology and applications: a scoping review protocol. BMJ Open 2022;12:e058069. doi:10.1136/ bmjopen-2021-058069

- Prepublication history and additional supplemental material for this paper are available online. To view these files, please visit the journal online (http://dx.doi.org/10.1136/ bmjopen-2021-058069).

Received 06 0ctober 2021 Accepted 02 February 2022

Check for updates

(c) Author(s) (or their employer(s)) 2022. Re-use permitted under CC BY-NC. No commercial re-use. See rights and permissions. Published by BMJ.

Australian Centre for Health Engagement, Evidence and Values, School of Health and Society, University of Wollongong, Wollongong, New South Wales, Australia

Correspondence to

Rebecca Bosward;

rbosward@uow.edu.au

\section{ABSTRACT}

Introduction Precision public health is an emerging and evolving field. Academic communities are divided regarding terminology and definitions, and what the scope, parameters and goals of precision public health should include. This protocol summarises the procedure for a scoping review which aims to identify and describe definitions, terminology, uses of the term and concepts in current literature.

Methods and analysis A scoping review will be undertaken to gather existing literature on precision public health. We will search CINAHL, PubMed, Scopus, Web of Science and Google Scholar, and include all documents published in English that mention precision public health. A critical discourse analysis of the resulting papers will generate an account of precision public health terminology, definitions and uses of the term and the use and meaning of language. The analysis will occur in stages: first, descriptive information will be extracted and descriptive statistics will be calculated in order to characterise the literature. Second, occurrences of the phrase 'precision public health' and alternative terms in documents will be enumerated and mapped, and definitions collected. The third stage of discourse analysis will involve analysis and interpretation of the meaning of precision public health, including the composition, organisation and function of discourses. Finally, discourse analysis of alternative phrases to precision public health will be undertaken. This will include analysis and interpretation of what alternative phrases to precision public health are used to mean, how the phrases relate to each other and how they are compared or contrasted to precision public health. Results will be grouped under headings according to how they answer the research questions.

Ethics and dissemination No ethical approval will be required for the scoping review. Results of the scoping review will be used as part of a doctoral thesis, and may be published in journals, conference proceedings or elsewhere.

\section{INTRODUCTION}

The term precision public health emerged in 2013, and its scope and definition are evolving. ${ }^{1}$ Precision public health stems from precision medicine and personalised medicine. ${ }^{12}$ These are individualised approaches to medicine that consider how factors such

\section{Strengths and limitations of this study}

- This is the first study of precision public health definitions, terminology, uses of the term and concepts in current literature, as few studies have attempted to collate and examine existing precision public health literature in a systematic way.

- Because the primary purpose of scoping reviews is to gather information from a wide variety of sources, this study will not evaluate quality of evidence.

- The inductive approach of the search strategy may potentially result in key phrases or search terms being missed in the search; however, the search strategy we described is the most robust to answer our research questions.

- Authors will use inter-rater reliability during both phases of the search strategy, and apply reflexivity throughout the research process to monitor progress of the search and to minimise bias. These measures are designed to increase replicability of results. However, the analysis relies on human judgement and interpretation so will, to some extent, reflect the knowledge and experience of the researchers.

- This study hinges on the use of the term precision public health. It is unlikely but possible that that some authors are writing about something similar to precision public health without using that term, and that they are not being cited by the authors we will find using our search strategy. This is unavoidable; the searching and analysis strategies we have devised are, in our view, the best way of scoping the relevant literature.

as genetics, environment and lifestyle can contribute to an individual's health or ill health. ${ }^{12}$ The goals of precision medicine are accurate and timely diagnosis, prevention and treatment based on individual needs, facilitated by technologies to process, analyse and store large volumes of data, such as electronic health records. ${ }^{1-3}$ Similarly, precision public health often relies on the use of technologies to collect, analyse and store precise genetic, environmental, social, behavioural and economic information. ${ }^{45}$ Broadly speaking, what distinguishes precision medicine from 
precision public health is a focus on individualised or tailored treatment for individuals on one hand, and targeted approaches that address population level health on the other. ${ }^{67}$

The most current approaches to precision public health leverage data from a wide variety of sources, include linked phenotype data, and use existing and new technologies and types of computation. ${ }^{7}$ This facilitates the collection and synthesis of massive amounts of data, which can be continuously updated and analysed. ${ }^{78}$ In comparison to traditional public health approaches, the promise is that this will enable more speedy and precise diagnosis of a public health issue. ${ }^{7-9}$ An example of this is geospatial risk modelling, which uses remote sensing technology to collect environmental data like rainfall or temperature to model distribution of an infectious disease. ${ }^{9}$

While the exact origins of the term precision public health are unclear, it appears to have emerged sometime in the 2010s. Dr Tarun Weeramanthri proposed use of the term in 2013, and several key conferences used the term around that time. ${ }^{10-12}$ There is an ongoing debate around what the scope, parameters, goals and definitions of precision public health should be $\mathrm{e}^{110-12}$

The ambiguities surrounding inconsistent definitions and use of terminology in precision public health may impact the progress of research. ${ }^{13}$ Vague definitions and concepts have also led to questions regarding the value of precision public health, including whether it is just a buzzword for what is already being achieved via conventional public health approaches. ${ }^{13-16}$ Some authors have proposed doing away with the term altogether. ${ }^{77-20}$ While debates have proliferated regarding precision public health, few studies have attempted to collate and examine existing relevant literatures in a systematic way. ${ }^{7}$

This scoping review will make a significant original contribution to the literature by mapping, synthesising and critiquing the growing body of knowledge on the definitions and terminology of precision public health and how these have evolved over time. It will also be useful for identifying emerging trends and patterns in the literature, and to systematically document and categorise uses of the term precision public health.

\section{Objectives}

The overarching aims of this scoping review are to identify and analyse the definitions of precision public health, uses of the term and adjacent or overlapping terminology, use of terms and concepts in the peer reviewed literature. We will answer the following research questions:

1. How has the term precision public health been used in the existing literature?

2. How have definitions and terminology of precision public health evolved over time?

3 . What claims are made about precision public health?
Systematically mapping definitions, terminology and uses of the term precision public health reported in existing literature could support future work to develop an agreed definition of precision public health, and to further conceptualise its goals, scope and parameters. It will also be useful to identify emerging trends and patterns in current literature.

\section{METHODS AND ANALYSIS}

This scoping review protocol adapts the approaches of McGowan $e t a l^{21}$ and Aromataris and Riitano, ${ }^{22}$ who developed evidence-based guidelines for systematic reviews, and Tricco et al, ${ }^{23}$ who developed the Preferred Reporting Items for Systematic reviews and Meta-Analyses extension for Scoping Reviews.

\section{Data management}

Citations will be downloaded into Endnote, and data cleaning will be performed using Endnote and SysRev. ${ }^{24}$ Data management will be done using NVivo ${ }^{25}$ and Microsoft Excel.

\section{Search strategy}

The scoping review will be conducted between December 2021 and December 2022. The search strategy will comprise two phases, a narrow search and a wide search. In phase one, we will search for the exact phrase 'precision public health' in CINAHL, PubMed, Scopus, Web of Science and Google Scholar. We checked sites for relevant protocols, and selected these databases based on their relevance and appropriateness as a source for scoping reviews. Inclusion criteria will be: (1) studies published in English; (2) use of the exact phrase 'precision public health' (as a complete phrase). Exclusion criteria will be: (1) words 'precision' 'public' or 'health' used but not as the exact phrase 'precision public health'; (2) exact phrase used but only in the references or author affiliations. We will not apply publication date limits. Addressing our aim to identify and describe terminology and definitions, this search will allow us to determine precisely how the term is being used, where it originated from and what other terms and definitions are used in association with it.

RB will search for the exact phrase 'precision public health' and download citations into Endnote. Full texts will be obtained and screened using the inclusion/ exclusion criteria. The full texts will then be reviewed to identify alternative terms to precision public health. Alternative terms will include anything that:

- Authors advocate as an alternative to precision public health

- Authors use interchangeably with precision public health

- Authors use commonly in association with precision public health 


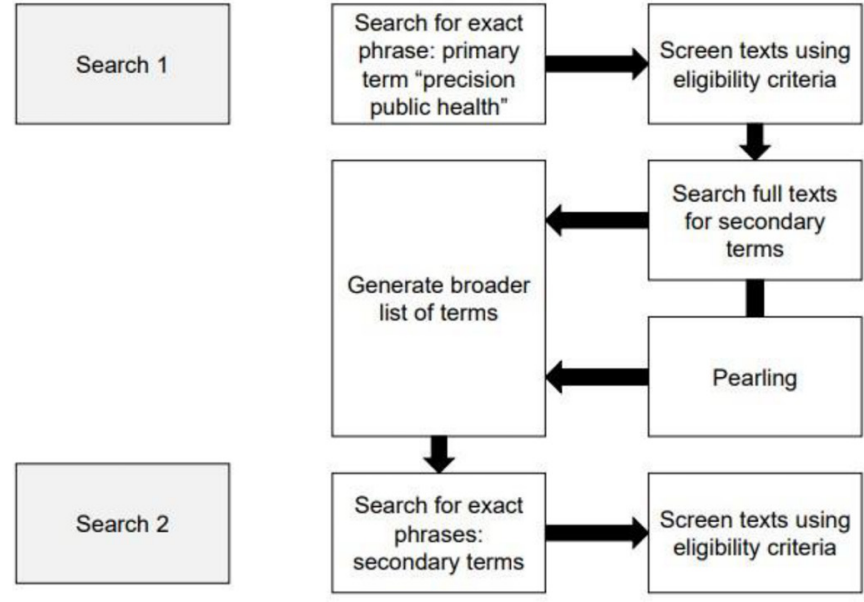

Figure 1 Flow chart of the scoping review search strategy.

This will contextualise the definition, and provide alternative or adjacent terminology, synonyms or overlapping concepts. RB will also search the reference lists of included articles to identify other citations that include alternative terms. ${ }^{26-28}$ All alternative terms identified in the results of the narrow search will be entered into a datasheet in Microsoft Excel, in order to catalogue their occurrence in citations. This will then be used to generate a broader list of search terms for phase two, which involves a wide search of the literature. Hereafter, precision public health will be referred to as the 'primary term', and alternative terms will be referred to as 'secondary terms'.

The second phase will involve a wide search of the literature to identify any additional citations that use secondary terms. RB will search for each secondary term as an exact phrase, combine the results and remove duplicates. Inclusion criteria will be: (1) documents published in English; (2) and mention of at least one of the secondary terms identified during search one. Exclusion criteria will be: (1) false drops, where words from the target term are used, but not in that exact phrase; (2) target term is mentioned only in the references or author affiliations.

The search strategy will be piloted in PubMed. ${ }^{29}$ The authors will collaborate on the progress of the search and resolve any issues that arise. The search strategy can also be updated if new terms are discovered. A summary of the search strategy can be seen in figure 1 .

\section{Article screening and selection}

All citations retrieved using the search strategy will be downloaded into Endnote. Automatic and manual searches of citations will be conducted to identify and remove duplicate references. Full texts will be then be retrieved through Endnote or via manual search and imported into SysRev for document screening. RB will scan full texts to determine if eligibility criteria has been met, and results will be discussed with the other authors. The final sample of documents will be imported into Microsoft Excel and NVivo for data extraction.

\section{Data extraction}

Descriptive variables will be extracted in Microsoft Excel. A coding framework for descriptive variables will be developed by the authors, adapted from other similar scoping review methods and standardised data extraction forms. ${ }^{21} 3031$ The framework will be updated as new information is uncovered, and already-coded articles recoded to ensure completeness. Articles will be imported into NVivo for data extraction.

\section{Data analysis}

The analysis will draw on critical discourse analysis, particularly drawing on the works of Ruth Wodak, Michael Meyer, Norman Fairclough, Siegfried Jäger and Teun van Dijk. ${ }^{32-38}$ It will also be informed by thematic synthesis and thematic discourse analysis methods, drawing on the works of Harden,$^{39}$ Rozbroj et $a t^{4041}$ and Botelle et at $t^{42}$

The analysis will contain both quantitative and interpretative stages. The first two stages of the analysis will be quantitative. First, we will extract data on descriptive variables, to enable analysis using descriptive statistics. RB will review articles to gain a preliminary understanding of their content, then extract descriptive information in Microsoft Excel. Variables will include author details, publication year, country of origin, country level of income, sector the article originates from (eg, public health), study type (eg, randomised control trial), study length, methods of data collection and analysis, funding and number of times the article has been cited. Descriptive statistics will include frequency counts of nominal variables and relative frequency distribution of nominal variables.

Articles will then be imported into NVivo and the data will be coded inductively using line-by-line coding, to enumerate occurrences of the phrase precision public health' and to collect and count secondary terms. ${ }^{39-42}$ This stage of analysis will count the use of primary and secondary terms, including use of the terms and definitions, and analyse how dominant terms are in each article for example, if the article is about precision public health, or if it is mentioned as an aside.

Stages one and two of analysis will be piloted prior to data extraction. A subset of $10 \%$ of documents will be selected using a random number generator in Microsoft Excel. To ensure reliability and accuracy of coding, two authors will code this subset, results will be compared and the coding frame finalised through discussion. ${ }^{39-44}$ A second subset of $10 \%$ of documents will then be extracted using the same method for inter-rater reliability testing, with coding again by two authors. Interrater reliability will be tested using the kappa statistic, or k Fleiss statistic. ${ }^{43} 44$ This will be calculated in Microsoft Excel and used to measure the extent of agreement between the two reviewers. ${ }^{434}$ Once the coding strategy has been finalised and inter-rater reliability is acceptable, 
RB will perform data extraction and analysis on all documents and the authors will review results. Any disagreements will be resolved by discussions with the authors and documented.

These first two stages of analysis will establish a timeline of how the phrase precision public health came into existence and developed, characterise terminology, definitions and uses of the term precision public health, as well as secondary terminology, definitions or concepts reported in literature. ${ }^{32} 34-364546$

The next stage of analysis will be interpretive and will focus on the analysis and interpretation of how the phrase 'precision public health' is used in literature, and the composition, organisation and function of discourses surrounding precision public health. ${ }^{32} 343547-54$ Discourses will be analysed from the macro to micro level. ${ }^{32} 343547-52$ Data will be coded in NVivo using line-by-line coding to group data into themes that reflect the content of each document. ${ }^{39-41} 5556$ We will undertake a qualitative analysis using the following framework:

- Intertextuality (macro): relationships between documents, such as how authors reference other sources, what other sources are referenced, how authors position their work in relation to other work, or how a document might influence new research. ${ }^{24-3232-365052-5457-59}$

- Context (meso): how context informs a discourse for example, the background of the authors, where the document was published, who the target audience is. 32 34-36465054

- Structure of documents (micro): how headings, subheadings and formatting shape themes or discourses, and the role of the introduction and conclusion. 32505357

- Linguistics (micro): how discourses function as language and inform the logic of an argument. ${ }^{32} 32-365051$ This will include the context of language, grammar, literary phrases, modalities and evidentiary language. ${ }^{32} 34-36465051$

The final stage of analysis will be interpretive and will focus on the analysis and interpretation of what secondary terms are used to mean, how the terms relate to each other, who is using them and how they are contrasted or paralleled with precision public health. Data will be coded inductively by grouping sentences or whole sections of text into themes that reflect the content of each document. $^{39-415556}$

The authors will apply reflexivity throughout the research process to improve transparency of methods and validity of results. ${ }^{39-41} 60$ This will include reflection on how personal experiences, biases, beliefs and attitudes may have affected study design, and methods of analysis and interpretation. ${ }^{39-4160-63}$ Reflexivity will also be addressed in any literature published from this research. ${ }^{39-41} 4563$

\section{Patient and public involvement statement}

No patient involved

\section{CONCLUSION}

This protocol summarises the procedure for a scoping review which aims to identify, describe and analyse definitions, terminology, uses of the term precision public health and emerging trends or patterns in current literature. Our findings will add to the growing body of knowledge on precision public health and aid conceptualisation of its goals, scope and parameters, and help guide the future of this emerging sub-discipline of public health.

Contributors RB designed and drafted the scoping review protocol. AB-M and $\mathrm{SC}$ each contributed by reviewing, editing and consulting on protocol design, and made substantial contributions to the drafting and critical revision of the work. EF contributed by reviewing, editing and consulting on protocol design. All authors contributed to subsequent revisions and approved the protocol prior to its submission

Funding The authors have not declared a specific grant for this research from any funding agency in the public, commercial or not-for-profit sectors.

Competing interests None declared.

Patient consent for publication Not required.

Provenance and peer review Not commissioned; externally peer reviewed.

Supplemental material This content has been supplied by the author(s). It has not been vetted by BMJ Publishing Group Limited (BMJ) and may not have been peer-reviewed. Any opinions or recommendations discussed are solely those of the author(s) and are not endorsed by BMJ. BMJ disclaims all liability and responsibility arising from any reliance placed on the content. Where the content includes any translated material, BMJ does not warrant the accuracy and reliability of the translations (including but not limited to local regulations, clinical guidelines, terminology, drug names and drug dosages), and is not responsible for any error and/or omissions arising from translation and adaptation or otherwise.

Open access This is an open access article distributed in accordance with the Creative Commons Attribution Non Commercial (CC BY-NC 4.0) license, which permits others to distribute, remix, adapt, build upon this work non-commercially, and license their derivative works on different terms, provided the original work is properly cited, appropriate credit is given, any changes made indicated, and the use is non-commercial. See: http://creativecommons.org/licenses/by-nc/4.0/.

\section{ORCID iDs}

Rebecca Bosward http://orcid.org/0000-0002-3368-0781

Annette Braunack-Mayer http://orcid.org/0000-0003-4427-0224

Emma Frost http://orcid.org/0000-0002-5893-1399

Stacy Carter http://orcid.org/0000-0003-2617-8694

\section{REFERENCES}

1 Weeramanthri TS, Dawkins HJ, Baynam G. Precision public health. Front Public Health 2018;6:121.

2 Prosperi M, Min JS, Bian J, et al. Big data hurdles in precision medicine and precision public health. BMC Med Inform Decis Mak 2018;18:1-5.

3 Sucharew $\mathrm{H}$, Macaluso M. Progress notes: methods for research evidence synthesis: the scoping review approach. J Hosp Med 2019;14:416-8.

4 Khoury MJ. Precision public health and precision medicine: two peas in a pod. centers for disease control and prevention, 2015. Available: https://blogs.cdc.gov/genomics/2015/03/02/precision-public/ [Accessed 4 Apr 2021].

5 Khoury MJ, Bowen MS, Clyne M, et al. From public health genomics to precision public health: a 20-year journey. Genet Med 2018;20:574-82.

6 Meyer SL. Toward precision public health. J Public Health Dent 2020;80 Suppl 1:S7-13.

7 Dolley S. Big data's role in precision public health. Front Public Health 2018;6:68.

8 Tonidandel S, King EB, Cortina JM. Big data methods: Leveraging modern data analytic techniques to build organizational science. Organ Res Methods 2018;21:525-47. 
9 Malone JB, Bergquist R, Martins M, et al. Use of geospatial surveillance and response systems for vector-borne diseases in the elimination phase. Trop Med Infect Dis 2019;4:15.

10 University of California San Francisco. Precision Public Health Summit: The First 1,000 Days [Internet]. California: University of California San Francisco. Available: https://www.ucsf.edu/precisionpublic-health-summit-first-1000-days\#: :text=On\%20June $\% 206 \%$ 2D7\%2C\%202016,improve\%20population\%20health\%20and\% 20equity [Accessed 17 Dec 2021].

11 Saw Swee Hock School of Public Health. Precision Public Health: Transforming Health with Data [Internet]. Singapore: National University of Singapor. Available: https://sph.nus.edu.sg/2021/04/ precision-public-health-transforming-health-with-data/ [Accessed 17 Dec 2021].

12 Eshelman School of Pharmacy. Transdisciplinary Conference for Future Leaders in Precision Public Health [Internet]. North Carolina: University of North Carolina. Available: https://pharmacy.unc.edu/ pharmsci2021/ [Accessed 17 Dec 2021].

13 Milwid R, Steriu A, Arino J, et al. Toward standardizing a lexicon of infectious disease modeling terms. Front Public Health 2016;4:213.

14 Olstad DL, McIntyre L. Reconceptualising precision public health. BMJ Open 2019;9:e030279.

15 Kee F, Taylor-Robinson D. Scientific challenges for precision public health. J Epidemiol Community Health 2020;74:311-4.

16 Taylor-Robinson D, Kee F. Precision public health-the Emperor's new clothes. International J Epidemiol 2019;48:1-6.

17 Bayer R, Galea S. Seeking precision in public health. Nat Med 2019;25:1177.

18 Carreiro S, Chai PR, Carey J, et al. Integrating personalized technology in toxicology: sensors, smart glass, and social media applications in toxicology research. J Med Toxicol 2017;13:166-72.

$19 \mathrm{Gu}$ D, Li J, Li X, et al. Visualizing the knowledge structure and evolution of big data research in healthcare informatics. Int $\mathrm{J}$ Med Inform 2017;98:22-32.

20 McGregor C. Using constructive research to structure the path to transdisciplinary innovation and its application for precision public health with big data analytics. Technology Innovation Management Review 2018;8:7-15.

21 McGowan J, Sampson M, Salzwedel DM, et al. PRESS Peer Review of Electronic Search Strategies: 2015 Guideline Statement. J Clin Epidemiol 2016;75:40-6.

22 Aromataris E, Riitano D. Constructing a search strategy and searching for evidence. Am J Nurs 2014:114:49-56.

23 Tricco AC, Lillie E, Zarin W, et al. PRISMA extension for scoping reviews (PRISMA-ScR): checklist and explanation. Ann Intern Med 2018;169:467-73.

24 Insilica, LLC. Sysrev. Greer, South Carolina: United States of America: Insilica, LLC, 2021. https://sysrev.com/

25 QSR International. NVivo [internet. Victoria, Australia: QSR International Pty Ltd, 2021. https://www.qsinternational.com/nvivoqualitative-data-analysis-software/home

26 Charles Sturt University. Systematic and Systematic-like Reviews [Internet]. Wagga Wagga: Charles Sturt University, 202. https:// libguides.csu.edu.au/systematicreviews/run

27 Horsley T, Dingwall O, Sampson M. Checking reference lists to find additional studies for systematic reviews. Cochrane Database Syst Rev 2011 (;8:MR000026.

28 Skin care provided in an aged care facility. JBI Evid Synth 2004;2:1-33.

29 Ossom Williamson P, Minter ClJ. Exploring PubMed as a reliable resource for scholarly communications services. J Med Libr Assoc 2019;107:16-29.

30 Tricco AC, Lillie E, Zarin W, et al. A scoping review on the conduct and reporting of scoping reviews. BMC Med Res Methodol 2016;16:1-10.

31 Pham MT, Rajić A, Greig JD, et al. A scoping review of scoping reviews: advancing the approach and enhancing the consistency. Res Synth Methods 2014;5:371-85.

32 Schneider F. How to Do a Discourse Analysis. In: Schneider F, ed. Politics East Asia [blog on the internet]. Netherlands: Florian Schneider: Leiden University, 2013. http://www.politicseastasia.com/ studying/how-to-do-a-discourse-analysis/

33 Wodak R, Meyer M, eds. Methods of Critical Discourse Analysis. 2nd revised ed. London: SAGE Publications Ltd, 2001.

34 Fairclough N. Critical discourse analysis: the critical study of language. New York, US: Routledge, 2013.

35 Fairclough $\mathrm{N}$. Critical discourse analysis as a method in social scientific research. In: Wodak R, Meyer M, eds. Methods of critical discourse analysis. 2nd revised ed. London, ENG: SAGE Publications Ltd, 2001: 122-36. https://www.fib.unair.ac.id/jdownloads/Materi\% 20Kuliah/Magister\%20Kajian\%20Sastra\%20dan\%20Budaya/
Analisis\%20Wacana/methods_of_critical_discourse_analysis_ruth_ wodak and michael meyer sage publications 2001.pdf

36 Jäger S. Discourse and knowledge: Theoretical and methodological aspects of a critical discourse and dispositive analysis. In: Wodak $\mathrm{R}$, Meyer M, eds. Methods of critical discourse analysis. 2nd revised ed. London, ENG: SAGE Publications Ltd, 2001: 32-59. https://www. fib.unair.ac.id/jdownloads/Materi\%20Kuliah/Magister\%20Kajian\% 20Sastra\%20dan\%20Budaya/Analisis\%20Wacana/methods_of_ critical_discourse_analysis_ruth_wodak_and_michael_meyer_sage_ publications_2001.pdf

37 Fairclough N. Discourse and text: linguistic and intertextual analysis within discourse analysis. Discourse \& society 1992;3:193-217.

38 van Dijk TA. Multidisciplinary CDA: a plea for diversity. In: Wodak R, Meyer M, eds. Methods of critical discourse analysis. 2nd revised edition . London, ENG: SAGE Publications Ltd, 2001: 95-119. https://www.fib.unair.ac.id/jdownloads/Materi\%20Kuliah/Magister\% 20Kajian\%20Sastra\%20dan\%20Budaya/Analisis\%20Wacana/ methods_of_critical_discourse_analysis_ruth_wodak_and_michael meyer_sage_publications_2001.pdf

39 Thomas J, Harden A. Methods for the thematic synthesis of qualitative research in systematic reviews. BMC Med Res Methodol 2008;8:1-0.

40 Rozbroj T, Haas R, O'Connor DA, et al. How do patients and the public understand overtesting and overdiagnosis? A protocol for a thematic meta-synthesis of qualitative research. BMJ Open 2020;10:e037283.

41 Rozbroj T, Lyons A, Lucke J. The Mad leading the blind: perceptions of the vaccine-refusal movement among Australians who support vaccination. Vaccine 2019;37:5986-93.

42 Botelle R, Willott C, Birth WC. Birth, attitudes and placentophagy: a thematic discourse analysis of discussions on UK parenting forums. BMC Pregnancy Childbirth 2020;20:1-0.

43 Barbour RS. Checklists for improving rigour in qualitative research: a case of the tail wagging the dog? BMJ 2001;322:1115-7.

44 Belur J, Tompson L, Thornton A. Interrater reliability in systematic review methodology: exploring variation in coder decision-making. Sociol Methods Res 2018:0049124118799372.

45 Mc Mahon M, McGrat N, Keane N. Steps for Discourse Analysis. In: Quintessentialqual. Wordpress [blog on the internet. Ireland: University College Cork, 2015. https://discoursevsthematic. wordpress.com/2015/11/11/discourse-steps/

46 Ruiz Ruiz J. Sociological discourse analysis: methods and logic. Forum Qual Soc Res 2009;10 http://nbn-resolving.de/urn:nbn:de: 0114-fqs0902263

47 Hodges BD, Kuper A, Reeves S. Discourse analysis. BMJ Open 2008;337

48 Edwards D. Emotion discourse. Cult Psychol 1999;5:271-91.

49 Potter J, Wetherell M. Discourse and social psychology: beyond attitudes and behaviour. London, ENG: SAGE Publications Ltd, 1987.

50 Wodak R. The discourse-historical approach. In: Wodak R, Meyer $\mathrm{M}$, eds. Methods of critical discourse analysis. 2nd revised edition London, ENG: SAGE Publications Ltd, 2001: 63-93. https://www. fib.unair.ac.id/jdownloads/Materi\%20Kuliah/Magister\%20Kajian\% 20Sastra\%20dan\%20Budaya/Analisis\%20Wacana/methods of critical_discourse_analysis_ruth_wodak_and_michael_meyer_sage publications_2001.pdf

51 Fairclough N. Discourse and text: linguistic and intertextual analysis within discourse analysis. Discourse Soc 1992;3:193-217.

52 Meyer M. Between theory, method, and politics: positioning of the approaches to CDA. In: Wodak R, Meyer M, eds. Methods of critical discourse analysis. 2nd revised ed. London, ENG: SAGE Publications Ltd, 2001: 14-30. https://www.fib.unair.ac.id/jdownloads/Materi\% 20Kuliah/Magister\%20Kajian\%20Sastra\%20dan\%20Budaya/ Analisis\%20Wacana/methods_of_critical_discourse_analysis_ruth wodak and michael meyer sage publications 2001.pdf

53 van Dijk TA. Multidisciplinary CDA: a plea for diversity. In: Wodak R, Meyer M, eds. Methods of critical discourse analysis. 2nd revised edition. London, ENG: SAGE Publications Ltd, 2001: 95-119. https://www.fib.unair.ac.id/jdownloads/Materi\%20Kuliah/Magister\% 20Kajian\%20Sastra\%20dan\%20Budaya/Analisis\%20Wacana/ methods_of_critical_discourse_analysis_ruth_wodak_and_michael_ meyer_sage_publications_2001.pdf

54 Scollon R. Action and text: towards an integrated understanding of the place of text in social (inter)action, mediated discourse analysis and the problem of social action. In: Wodak R, Meyer M, eds. Methods of critical discourse analysis. 2nd revised edition London, ENG: SAGE Publications Ltd, 2001: 141-82. https://www. fib.unair.ac.id/jdownloads/Materi\%20Kuliah/Magister\%20Kajian\% 20Sastra\%20dan\%20Budaya/Analisis\%20Wacana/methods_of critical_discourse_analysis_ruth_wodak_and_michael_meyer_sage publications_2001.pdf 
55 Braun V, Clarke V. Using thematic analysis in psychology. Qual Res Psychol 2006;3:77-101.

56 Maguire M, Delahunt B. Doing a thematic analysis: a practical, step-by-step guide for learning and teaching scholars. AISHE 2017;9:3351-64.

57 Wang W. Newspaper commentaries on terrorism in China and Australia: A contrastive genre study [PhD Doctorate]. [Sydney (AU)]: University of Sydney, 2006. Available: https://ses.library.usyd.edu.au/ handle/2123/1701 [Accessed 22 May 2021].

58 Bazerman C. Intertextuality: how texts rely on other texts. In: What writing does and how it does it. New York, US: Routledge, 2003: 89-102.

59 Porter JE. Intertextuality and the discourse community. Rhetoric Review 1986;5:34-47.
60 Bosward R. Ethical perspectives of university students on informed consent for use of their data in higher education and research (thesis. Wollongong (AU): University of Wollongong, 2019.

61 Eubank BH, Mohtadi NG, Lafave MR, et al. Using the modified Delphi method to establish clinical consensus for the diagnosis and treatment of patients with rotator cuff pathology. BMC Med Res Methodol 2016;16:1-15.

62 Birks Y, Harrison R, Bosanquet K, et al. An exploration of the implementation of open disclosure of adverse events in the UK: a scoping review and qualitative exploration. Health Services and Delivery Research 2014;2:1-196.

63 Malterud K. Standards qualitative research: challenges, and guidelines. Lancet 2001;358:483-8. 